\title{
Patient reported outcome measures (PROMs) and patient reported experience measures (PREMs) for Dutch urolithiasis patients
}

\author{
Janneke B. M. Jacobs · Saskia Weltings · Rob C. M. Pelger - Barbara M. A. Schout
}

Published online: 23 January 2020

(c) The Author(s) 2020

\begin{abstract}
Measuring quality of care with Patient Reported Outcome Measures (PROMs) and Patient Reported Experience Measures (PREMs) is becoming increasingly important. With this study we evaluated ESWL and URS treatments with PROMs/PREMs and gained experience with the execution and implementation of PROMs/PREMs in daily practice. A longitudinal survey study was performed with ESWL and URS urolithiasis patients, using a questionnaire directly (T0-response $69.8 \%, n=51$ ) and 10 days after treatment (T1-response 56\%, $n=42$ ). Problems on performing daily activities were experienced by $54.2 \%$ of ESWL and $61.1 \%$ of URS-patients. In the two weeks after treatment $45.8 \%$ of the ESWL group and $70.6 \%$ of the URS-patients uses pain medication. URS-patients miss more workdays (5.61 versus $1.26 p=0.025$ ). Patient satisfaction is similar in both groups. With this study we have made a start with PROMs and PREMs for urolithiasis patients. It shows that urolithiasis treatment has influence on patient's life. More knowledge in this area will improve shared decision making.
\end{abstract}

Keywords patient reported outcome measures . PROMs · PREMS · urolithiasis · value based healthcare

\author{
drs. J. B. M. Jacobs ( $\bowtie)$ \\ Centrum Dubbele Problematiek Fivoor, Den Haag, The \\ Netherlands \\ janneke_jacobs@live.nl \\ drs. S. Weltings · prof. dr. R. C. M. Pelger \\ Leids Universitair Medisch Centrum, Leiden, The \\ Netherlands \\ dr. B. M. A. Schout \\ Alrijne Ziekenhuis, Leiderdorp, The Netherlands
}

Samenvatting Meten van kwaliteit van zorg met Patient Reported Outcome Measures (PROMs) en Patient Reported Experience Measures (PREMs) wordt steeds belangrijker. Met deze studie evalueerden we ESWLen URS-behandelingen met PROMs/PREMs en deden we ervaring op met het uitvoeren en implementeren van PROMs/PREMs in de praktijk. We verrichtten een longitudinaal onderzoek bij urolithiasispatiënten die werden behandeld met ESWL en URS door middel van een vragenlijst die direct na de behandeling werd afgenomen (T0-respons $69,8 \% ; n=51$ ) en 10 dagen na behandeling (T1-respons $56 \% ; n=42$ ). $54,2 \%$ van de patiënten in de ESWL-groep en $61,1 \%$ van de patiënten in de URS-groep ondervonden problemen met uitvoeren van dagelijkse activiteiten. In de twee weken na behandeling werden pijnstillers gebruikt door $45,8 \%$ van de patiënten in de ESWL-groep en $70,6 \%$ van de patiënten in de URS-groep. Het werkverzuim in de URS-groep lag hoger (5,61 vs. 1,26 dagen; $p=0,025$ ). De tevredenheid in beide groepen was gelijk. Met dit onderzoek hebben wij een start gemaakt met PROMs en PREMs bij urolithiasispatiënten. Analyse laat zien dat de behandeling impact heeft op het leven van de patiënt. Meer kennis op dit gebied kan worden toegepast bij het verbeteren van shared decision making.

Trefwoorden patient reported outcome measures . PROMs · PREMs · urolithiasis · value based healthcare

\section{Introduction}

Urolithiasis is a common disease with an incidence of $120-140$ per 100,000 per year [1]. The recurrence risk is high: $50 \%$ within 10 years [1], and with every episode this risk increases [2]. In the US, the annual medical costs of urolithiasis were estimated at 2.1 bn dollar [3]. With the high incidence, high recurrence risk and high 
costs, it can be concluded that urolithiasis is a major health care burden [4].

In recent years there has been a paradigm shift towards a more patient-centred view on healthcare. Where outcomes in the past years were measured according to factors the physician found important [5], in the future patients' opinion will evaluate outcomes. Value-based health care was introduced in 2006 and believes that improvement of healthcare should be patient-centred and outcomes should include health circumstances most relevant to patients [6]. To measure these aspects, PROMs and PREMs were developed [7]. These instruments measure the outcomes of patients health (PROMs), and the experience about a caring process (PREMs) $[8,9]$. As PROMs and PREMs have become important to measure the value of healthcare, more instruments are being developed to do so.

Value based healthcare and PROMs and PREMs are also considered important in urology. However, PROMs and PREMs for urolithiasis fall behind [10]. To demonstrate: in 2010 there were 16 validated instruments for prostate cancer, 11 for benign prostate hyperplasia and 24 for urinary incontinence [4]. However, there is only one disease specific validated PROM for urolithiasis $[4,11]$ and this questionnaire is only for the evaluation of living with kidney stones, and not for the evaluation of urolithiasis treatment.

Next to this, the generic patient reported outcomes measurement information system (PROMIS) had been validated for urolithiasis patients. This questionnaire has been used to evaluate treatment for urolithiasis, but no items about specific urological symptoms are included. This study showed that urolithiasis patients subjectively have worse pain and physical functioning compared to the general population [12] and evaluated the impact of urolithiasis on quality of life.

This study was designed to evaluate treatment for urolithiasis, using the patient-centred view and also to improve PROMs and PREMs for urolithiasis and to gain experience in performing and implementing PROMs in daily practice. We aimed to answer the following question: how do urolithiasis patients assess their treatment with ESWL or URS regarding to quality of life, pain, symptoms, and PREMs?

\section{Methods}

\section{Study design}

This study is a prospective longitudinal survey study performed at Alrijne Health Group, location Leiderdorp.

\section{Participants, inclusion and recruitment}

Participants were enrolled at Alrijne Health Group. To meet the inclusion criteria, patients had to have urolithiasis and receive treatment with ESWL or URS. They had to be 18 years or older, mentally competent and able to speak and understand Dutch. All patients treated with URS or ESWL between July 9th and October 5th in 2018, who met the inclusion criteria, were asked permission to participate in the study. Patients were enrolled at the urology clinic or the outpatient department. If they agreed to participate, written informed consent was obtained.

\section{Data collection}

Demographic data, medical history and treatment information were collected from the electronic patient data system.

Patients were asked to fill in two questionnaires. The first questionnaire was administered directly after the treatment (for ESWL patients), or the day after the treatment (for URS patients). The second questionnaire had to be filled in 10 days after the treatment. Patients filled in the questionnaires on an iPad, using the program Explora Zorg (made by the Dutch Association of hospitals), or on paper.

The first questionnaire was filled in in the outpatient (ESWL) or inpatient (URS) clinic and consisted of two parts. In the first part, patients were asked about the seven days before the treatment. This was the baseline measurement. In the second part, participants had to answer questions about the treatment. The second questionnaire was filled in 10-14 days after the treatment, either when visiting the outpatient department or using email at home. Both questionnaires contained 25 items.

\section{Questionnaires}

PROMS in general exist of two parts: general and disease specific PROMS. For the general PROMS part we used the EQ5D-5L [13], which is a globally acknowledged validated questionnaire. This measures quality of life on five dimensions: mobility, self-care, daily activities, pain/discomfort and anxiety/depression. Pain was measured by PROMIS Pain Intensity. With this questionnaire patients scored their maximal and average pain on a five-points scale $(1=$ no pain, $5=$ very severe pain). Some other items for general PROMS were retrieved from the RAND-36 [14].

For the disease-specific questions, we used a selection of questions about symptoms (haematuria, burning sensation while urinating, fever and urgency), which were based on the Wisconsin Stone Questionnaire [11] and supplemented with 'common sense' questions.

The compiling of the questionnaire was done by the research team (two urologists, one urology resident and one student). The questionnaire was piloted among seven urolithiasis patients treated with ESWL or URS, who tested the questionnaire and provided the research team with feedback. It took the pilot patients among $10 \mathrm{~min}$ to fill in the questionnaires. 


\section{Artikel}

\section{Statistical analysis}

The statistical analysis was performed using IBM SPSS Statistics version 25. Dichotomous variables were analysed using frequency tables and testing was performed using McNemar and Chi Square tests. Nominal and ordinal variables were analysed using median and range and testing was performed using Wilcoxon and Mann-Whitney test. Numeric variables, if normally distributed, were analysed using mean and standard deviation and testing was performed with $t$-tests.

\section{Results}

Demographic and clinical characteristics of patients included can be found in Tab. 1. During the study period, 74 patients were eligible and 51 patients were finally included.

Table 1 Demographic and clinical characteristics of the patients included

\begin{tabular}{|c|c|c|c|c|}
\hline & $\begin{array}{l}\text { ESWL patients } \\
\text { baseline } \\
n=29(\%)\end{array}$ & $\begin{array}{l}\text { ESWL patients } \\
\text { treatment and follow-up } \\
n=24(\%)\end{array}$ & $\begin{array}{l}\text { URS patients } \\
\text { baseline } \\
n=22(\%)\end{array}$ & $\begin{array}{l}\text { URS patients } \\
\text { treatment and follow-up } \\
n=18(\%)\end{array}$ \\
\hline \multicolumn{5}{|c|}{ Patient characteristics } \\
\hline \multicolumn{5}{|c|}{ Gender } \\
\hline Male & 25 (86.2) & $22(91.7)^{\star}$ & $14(63.6)$ & $11(61.1)^{\star}$ \\
\hline Female & $4(13.8)$ & $2(8.3)$ & $8(36.4)$ & $7(38.9)$ \\
\hline Age & Median 56 (28-81) & Median 56 (28-81) & Median 60 (42-79) & Median 60 (39-81) \\
\hline$B M I$ & $\begin{array}{l}\text { Median 26.9 } \\
(21.0-41.5)\end{array}$ & Median $26.6(21.0-30.5)$ & $\begin{array}{l}\text { Median 26.9 } \\
(20.6-54.2)\end{array}$ & Median $26.6(20.6-54.2)$ \\
\hline \multicolumn{5}{|l|}{ Stone history } \\
\hline First time stone former & $19(70.4)$ & $16(72.7)$ & $8(36.4)$ & $7(38.9)$ \\
\hline Recurrent stone former & $8(27.5)$ & $6(27.3)$ & $14(63.6)$ & $11(61.1)$ \\
\hline \multicolumn{5}{|c|}{ Number of ESWL/URS treatment for this particular stone } \\
\hline 1 & $17(68.0)$ & $14(70.0)$ & $22(100)$ & $18(100)$ \\
\hline 2 & $5(20.0)$ & $5(25.0)$ & & \\
\hline 3 & $2(8.0)$ & $1(5.0)$ & & \\
\hline 4 & $1(3.4)$ & $0(0.0)$ & & \\
\hline \multicolumn{5}{|l|}{ Stone characteristics } \\
\hline Diameter (mm) & Mean 6.52 (SD 1.84) & Mean $6.74(1.93)^{\star}$ & Mean 8.16 (SD 3.41) & Mean $8.69(\text { SD } 3.36)^{\star}$ \\
\hline HU value & Mean 869.5 (SD 215.3) & Mean $881.2(S D 237.9)^{*}$ & Mean 966.5 (SD 375.9) & Mean $1001.9\left(\right.$ SD 384.4) ${ }^{\star}$ \\
\hline \multicolumn{5}{|l|}{ Stone position } \\
\hline Kidney & $10(37.0)$ & $7(31.8)$ & $5(22.7)$ & $5(27.9)$ \\
\hline Ureter & $17(63.0)$ & $15(62.5)$ & $16(72.7)$ & 13 (72.2) \\
\hline - Distal ${ }^{\mathrm{a}}$ & $11(40.7)$ & $10(45.5)$ & $5(22.7)$ & $5(27.8)$ \\
\hline - Proximal & $6(22.2)$ & $5(22.7)$ & $11(50.0)$ & $8(44.4)$ \\
\hline \multicolumn{5}{|c|}{ Treatment characteristics } \\
\hline Shock waves & Mean 3519.2, SD 98.1 & Mean 3525, SD 111.8 & & \\
\hline Frequency & Mean 59.4, SD 17.6 & Mean 61.4, SD 14.6 & & \\
\hline Hospital admission ${ }^{b}$ & $3(9.9)$ & $2(8.2)$ & & \\
\hline \multicolumn{5}{|l|}{ Hospital discharge } \\
\hline Same day & & & $1(5.3)$ & $1(6.3)$ \\
\hline+1 day & & & $17(89.5)$ & $14(87.5)$ \\
\hline$>+2$ days & & & $1(5.3)$ & $1(6.3)$ \\
\hline Operating time (minutes) & & & Mean 36.81 (SD 15.1) & Mean 36.25 (SD 16.0) \\
\hline \multicolumn{5}{|c|}{ Stonefree after one treatment ${ }^{c}$} \\
\hline Yes $^{\mathrm{C}}$ & $3(12.5)$ & $3(15.8)$ & $19(90.5)$ & $16(88.9)$ \\
\hline Changes in stone & $6(25.0)$ & $6(31.6)$ & 0 & 0 \\
\hline No & $15(62.5)$ & $10(52.6)$ & $2(9.5)$ & $2(11.1)$ \\
\hline
\end{tabular}

82 Patient reported outcome measures (PROMs) and patient reported experience measures (PREMs) for Dutch... 
Table 2 EQ5D-5L questionnaire outcomes

\begin{tabular}{|c|c|c|c|c|}
\hline Dimension & ESWL baseline & ESWL follow up & URS baseline & URS follow up \\
\hline \multicolumn{5}{|l|}{ Mobility } \\
\hline I have no problems in walking about & $91.7 \%(22)$ & $91.7 \%(22)$ & $66.7 \%(12)$ & $66.7 \%(12)$ \\
\hline I have slight problems in walking about & $4.2 \%(1)$ & $8.4 \%(2)$ & $16.7 \%(3)$ & $27.8 \%(5)$ \\
\hline I have moderate problems in walking about & 0 & 0 & $5.6 \%(1)$ & 0 \\
\hline I have severe problems in walking about & $4.2(1)$ & 0 & $5.6 \%(1)$ & $5.6 \%(1)$ \\
\hline I am unable to walk about & 0 & 0 & $5.6 \%(1)$ & 0 \\
\hline \multicolumn{5}{|l|}{ Self-care } \\
\hline I have no problems washing or dressing myself & $95.8 \%(23)$ & $95.8 \%(23)$ & $88.9 \%(16)$ & $94.4 \%(17)$ \\
\hline I have slight problems washing or dressing myself & $4.2 \%(1)$ & $4.2 \%(1)$ & 0 & 0 \\
\hline I have moderate problems washing or dressing myself & 0 & 0 & $5.6 \%(1)$ & 0 \\
\hline I have severe problems washing or dressing myself & 0 & 0 & 0 & $5.6 \%(1)$ \\
\hline I am unable to wash or dress myself & 0 & 0 & $5.6 \%(1)$ & 0 \\
\hline \multicolumn{5}{|l|}{ Usual activities } \\
\hline I have no problems doing my usual activities & $70.8 \%(17)$ & $45.8 \%(11)$ & $38.9 \%(7)$ & $38.9 \%(7)$ \\
\hline I have slight problems doing my usual activities & $16.7 \%(4)$ & $29.2 \%(7)$ & $22.2 \%(4)$ & $33.3 \%(6)$ \\
\hline I have moderate problems doing my usual activities & $4.2 \%(1)$ & $12.5 \%(3)$ & $16.7 \%(3)$ & $22.2 \%(4)$ \\
\hline I have severe problems doing my usual activities & $8.3 \%(2)$ & $12.5 \%(3)$ & $16.7 \%(3)$ & $1(5.6)$ \\
\hline I am unable to do my usual activities & 0 & 0 & $5.6 \%(1)$ & 0 \\
\hline \multicolumn{5}{|l|}{ Pain/discomfort } \\
\hline I have no pain or discomfort & $41.7 \%(10)$ & $41.7 \%(10)$ & $11.1 \%(2)$ & $33.3(6)$ \\
\hline I have slight pain or discomfort & $20.8 \%(5)$ & $29.2 \%(7)$ & $38.9 \%(7)$ & $27.8 \%(5)$ \\
\hline I have moderate pain or discomfort & $20.8 \%(5)$ & $12.5 \%(3)$ & $22.2 \%(4)$ & $33.3(6)$ \\
\hline I have severe pain or discomfort & $4.2 \%(1)$ & $16.7 \%(4)$ & $22.2 \%(4)$ & 0 \\
\hline I have extreme pain or discomfort & 0 & 0 & $5.6(1)$ & $5.6(1)$ \\
\hline \multicolumn{5}{|l|}{ Anxiety/depression } \\
\hline I am not anxious or depressed & $79.2 \%(19)$ & $87.5 \%(21)$ & $72.2 \%(13)$ & $77.8 \%(14)$ \\
\hline I am slightly anxious or depressed & $20.8 \%(5)$ & $4.2 \%(1)$ & $16.7 \%(3)$ & $11.1 \%(2)$ \\
\hline I am moderately anxious or depressed & 0 & $8.3 \%(2)$ & $5.6 \%(1)$ & $11.1 \%(2)$ \\
\hline I am severely anxious or depressed & 0 & 0 & $5.6 \%(1)$ & 0 \\
\hline I am extremely anxious or depressed & 0 & 0 & 0 & 0 \\
\hline
\end{tabular}

\section{Quality of life}

The outcomes of EQ5D-5L by dimension can be found in Tab. 2. This questionnaire contains five items: mobility, self-care, usual activities, pain/discomfort and anxiety/depression. Patients reported about these items about the 7 days prior to treatment (baseline) and 10-14 days after treatment (follow-up). The item that stands out is usual activities. On baseline, in the ESWL group $70.8 \%$ of patients report problems doing usual activities; $16.7 \%(n=4)$ report slight problems, $4.2 \%(n=1)$ report moderate problems and $8.3 \%$ $(n=2)$ report severe problems in doing usual activities. AT follow-up the number of patients that report problems in doing usual activities rises; no problems $45.8 \%(n=11)$, slight problems $29.2 \%(n=7)$, moderate problems $12.5 \%(n=3)$, severe problems $12.5 \%(n=3)$.

On baseline in the URS group $38.9 \%(n=7)$ report to have no problems doing usual activities, $22.2 \%(n=4)$ slight problems, $16.7 \%(n=3)$ report moderate problems, $16.7 \%(n=3)$ report severe problems and $5.6 \%$ $(n=1)$ report to be unable to do usual activities. The scores at follow-up are; $38.9 \%(n=7)$ no problems, 33.3\% $(n=6)$ slight problems, 22.2\% $(n=4)$ moderate problems and $15.6 \%(n=1)$ severe problems.

For all but one item on the EQ5D-5L, there was no difference between ESWL and URS group on baseline or follow up. The only score that was different between ESWL and URS was usual activities on baseline $(p=0.04)$.

Combining the two groups, there was no difference in QoL between men and women and between recurrent stone formers or first-time stone formers, also age and stone size placement did not statistically influence QoL.

Off the 23 working ESWL patients, $30.4 \%(n=7)$ had to call in sick after treatment compared to $61.5 \%$ $(n=8)$ of the 13 working URS patients. URS patients miss significantly more workdays compared to ESWL treated patients, 5.61 vs 1.26 ( $p=0.025$ ).

Patients were asked to rate their own health and quality of life on a scale from 1 'very bad' to 7 'excellent'. 
In the ESWL group, the mean baseline score for perceived health was 5.83 (SD 1.01), and at follow-up 5.79 (SD 0.98). The mean baseline score for perceived quality of life was 5.89 (SD 1.12) and at follow-up 5.83 (SD 1.12).

For perceived health in the URS group the mean baseline score was 4.83 (SD 1.43), and at follow-up 5.00 (SD 1.46). For perceived quality of life, on baseline mean was 5.00 (SD 1.32). At follow-up this score was 5.50 (SD 1.24). These scores do not differ between baseline and follow-up.

There was no difference for perceived health and quality of life between ESWL and URS on baseline as well as on follow-up.

\section{Pain}

\section{Average pain level}

The outcomes for average pain level are shown in Tab. 3 and Fig. 1.

Patients scored their average pain' and their 'maximal pain' on a five point scale as used in the PROMIS pain intensity [12] ranging from 1 'no pain' to 5 'very severe pain'. URS patients filled in the questionnaire the morning after the surgery. ESWL patient filled in the questionnaire directly after the treatment.

For URS patients: at T0 they filled in their pain levels in the 7 days before admission in the hospital ('baseline') and since the surgery ('after treatment'). At $\mathrm{T} 1$ they filled in their current pain level and the maximum pain level in the last 7 days. For ESWL patients: at T0 they reported their pain levels in the 7 days before admission in the hospital ('baseline') and at that moment ('after treatment'). At T1 they filled in their current pain level and the maximum pain level in the last 10-14 days.
The standard analgesia during the ESWL is paracetamol $1000 \mathrm{mg}$. For the URS, the standard analgesia is paracetamol 4 times a day $1000 \mathrm{mg}$. If pain medication was insufficient for URS and ESWL, additional diclofenac could be prescribed. For both the ESWL and URS, the advised pain medication after treatment is 4 times a day paracetamol $1000 \mathrm{mg}$.

For average pain on baseline, analysis showed no difference between the ESWL and the URS group. During hospital admission, URS treated patients experience significantly more pain than ESWL treated patients $(p=0.01)$. Two weeks after treatment, average pain is similar between the two groups.

\section{Maximum pain level}

The outcomes of maximum pain level are shown in Tab. 4 and Fig. 2.

The maximum pain score at baseline is higher in URS group compared to the ESWL group $(p=0.02)$. During treatment and two weeks after treatment, the maximal pain is similar between the two groups.

One of the items on the EQ5D-5L is pain/discomfort In the ESWL group, on baseline $41.7 \%(n=10)$ state to have no pain/discomfort, $20.8 \%(n=5)$ state to have slight pain/discomfort, $20.8 \%(n=5)$ states to have moderate pain/discomfort and $4.2 \% \quad(n=1)$ state to have severe pain or discomfort. At followup $41.7 \%(n=10)$ report no pain/discomfort, $29.2 \%$ $(n=7)$ slight pain/discomfort, $12.5 \%(n=3)$ moderate pain/discomfort and $16.7 \%(n=4)$ severe pain/ discomfort.

In the URS group on baseline, $38.9 \%(n=7)$ report no pain/discomfort, $22.2 \%(n=4)$ slight pain/ discomfort, $16.7 \%(n=3)$ moderate pain/discomfort, $16.7 \%$ severe pain/discomfort and $5.6 \%(n=1)$ extreme pain/discomfort. At follow-up, the scores on

Table 3 Outcomes average pain level (PROMIS pain intensity)

\begin{tabular}{|c|c|c|c|c|c|}
\hline & No pain & Mild pain & Reasonable pain & Severe pain & Very severe pain \\
\hline & $n(\%)$ & & & & \\
\hline URS baseline & $4(22.2)$ & $9(50.0)$ & $3(16.7)$ & $1(5.6)$ & $1(5.6)$ \\
\hline URS treatment & $3(16.7)$ & $6(33.3)$ & $8(44.4)$ & $1(5.6)$ & 0 \\
\hline URS follow up & $8(47.1)$ & $5(29.4)$ & $3(17.6)$ & 0 & $1(5.9)$ \\
\hline ESWL baseline & $14(58.3)$ & $6(25.0)$ & $2(8.3)$ & $1(4.2)$ & $1(4.2)$ \\
\hline ESWL treatment & $13(54.2)$ & $9(37.5)$ & $2(8.3)$ & 0 & 0 \\
\hline ESWL follow up & $12(50.0)$ & $7(29.2)$ & $5(20.8)$ & 0 & 0 \\
\hline
\end{tabular}

Table 4 Outcomes maximum pain level (PROMIS pain intensity)

\begin{tabular}{|c|c|c|c|c|c|}
\hline & No pain & Mild pain & Reasonable pain & Severe pain & Very severe pain \\
\hline & $n(\%)$ & & & & \\
\hline URS baseline & $1(5.6)$ & $7(38.9)$ & $2(11.1)$ & $6(33.3)$ & $2(11.1)$ \\
\hline URS treatment & $4(22.2)$ & $3(16.7)$ & $5(27.8)$ & $3(16.7)$ & $3(16.7)$ \\
\hline URS follow up & $3(16.7)$ & $5(27.8)$ & $4(23.5)$ & $3(17.6)$ & $2(11.8)$ \\
\hline ESWL baseline & $11(45.8)$ & $7(29.2)$ & $1(4.2)$ & $2(8.3)$ & $3(12.5)$ \\
\hline ESWL treatment & $5(20.8)$ & $11(45.8)$ & $7(29.2)$ & $1(4.2)$ & 0 \\
\hline ESWL follow up & $4(16.7)$ & $8(33.3)$ & $6(25.0)$ & $5(20.8)$ & $1(4.2)$ \\
\hline
\end{tabular}




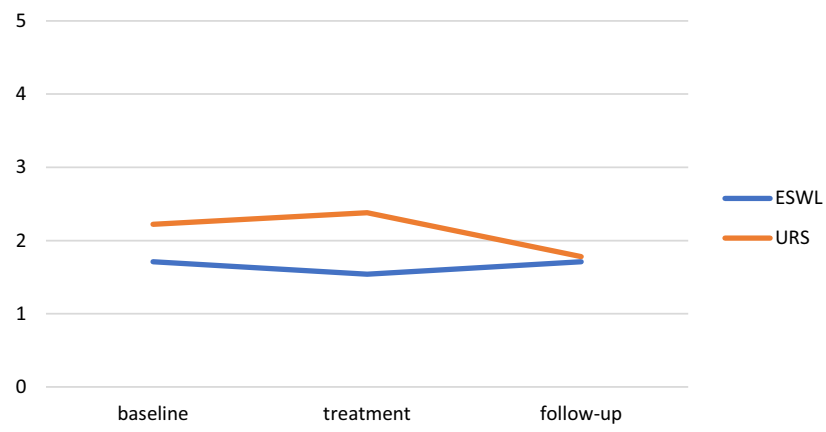

Fig. 1 Average pain level

the items were: $33.3 \%(n=6)$ no pain/discomfort, $27.8 \% \quad(n=5)$ slight pain/discomfort, 33.3\% $\quad(n=6)$ moderate pain/discomfort, 0 severe pain/discomfort and $5.6 \%(n=1)$ extreme pain/discomfort. For this item, there was no difference between the ESWL and URS group on baseline and follow up.

Of the ESWL group, $45.8 \%(n=11)$ reports to have used analgesics in the two weeks after treatment compared to $70.6 \%(n=13)$ of the URS group ( $p=0.116)$.

In the ESWL group, $20.8 \%$ state to have had contact with the outpatient clinic urology or their own general practitioner for additional pain medication in the 10-14 days after treatment. In the URS group this is $23.5 \%$.

\section{Symptoms}

In Fig. 3, the results are shown for the following experienced symptoms: haematuria, burning sensation while urinating, fever, urgency.

There is no difference in the ESWL group between baseline and follow up for the symptoms haematuria, burning sensation while urinating and urgency. Fever is almost not experienced by urolithiasis patients; at baseline two patients $(8.4 \%)$ and after treatment one patient $(4.2 \%)$.

The amount of patients in the ESWL group who develop symptoms at follow up and did not experience these symptoms at baseline is $12.5 \%(n=3)$ for haematuria and $4.2 \%(n=1)$ for a burning sensation while urinating.

In the URS group there are no differences between the occurrence of the above named symptoms regarding baseline and follow up. Fever is experienced by three patients $(16.7 \%)$ in the week before treatment and by two patients after treatment (11.8\%).

The amount of patients in the URS group who develop symptoms at follow up which they did not experience at baseline was $31.7 \%(n=5)$ for haematuria and $29.4 \%(n=5)$ for a burning sensation while urinating. When comparing symptoms between the ESWL and URS group, there is no difference in the incidence of haematuria, burning sensation while urinating, fever and urgency on baseline as well as follow up.

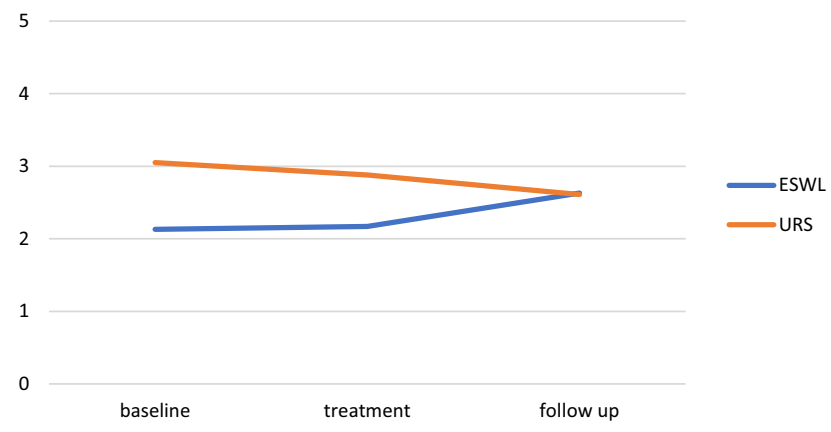

Fig. 2 Maximum pain level

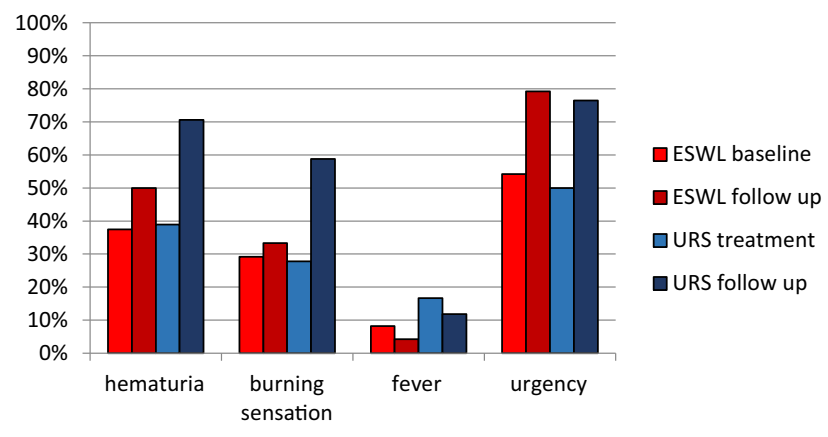

Fig. 3 Symptoms before and after treatment

\section{PREMs}

Median score in all of the groups was 4.00 which equals 'satisfied'. In both treatment groups patients are equally satisfied about the doctor and the nurses, the overall experience on baseline and the overall experience at follow-up.

\section{Discussion}

With this study we have made a start with evaluating treatment with ESWL and URS for urolithiasis patients by using PROMs and PREMs in the Netherlands. This study shows that urolithiasis treatment has influence on patient's life (especially on the items doing usual activities and pain/discomfort), and that it is important that in future we will have this information next to technical outcome information. This valuable information can be used in the patient-doctor conversations and making treatment-decisions.

In the current time the additional value of usage PROMs and PREMs in healthcare is clear and no discussion. However, organisations have had mixed success in implementing PROMs, and the process of developing a specific PROM is intensive [15, 16]. Foster et al. clearly demonstrated the main barriers and facilitators in the implementation pathway of PROMs in their extended review of PROMS usage [15]. Stage 1 of PROMs process is defining purpose. In our opinion, to exactly identify the purpose and the gains of PROMs and PREMs for urolithiasis patients one has to have experience and see and feel in practice what infor- 
mation the specific PROMs and PREMs will yield for patients and doctors, rather that the purpose is established coming forward from a theoretical framework. Therefore, instead of a complex validation process, we started with gaining experience in daily practice. We see this as part of the first stage in defining purpose of PROMs development, in order to be able to efficiently get through the whole process further on. To come from the first step 'defining purpose' to actual implementation in routine daily use, we will have to go through a process. First initiatives have already been undertaken to organise this within the Stone Expertise Netherlands Network (SENN), and make use of tools provided for general proms development, such as provided by the Zorginstituut Nederland [16].

PROMs and PREMs in general consist of a general part (e.g. quality of life/pain) part and a disease specific part (e.g urological symptoms). As mentioned before, there is only one questionnaire that contains disease specific questions, but does not evaluate treatments [11]. And one another questionnaire does evaluate stone treatments, however only uses the parameter pain and no other QoL and no disease-specific questions [12]. In our study, we designed a combined generic and disease-specific questionnaire to evaluate ESWL and URS treatment. In the meantime of writing and revising this manuscript one generic and diseasespecific questionnaire has been published [17] and we have information that another publication with a questionnaire is on the way. We expect that in 2020 these two validated questionnaires from the United Kingdom (UK) will be available and within the SENN we will then have to decide whether we will validate a translated Dutch version of one of the UK's questionnaires or start the validation process of the questionnaire of this study.

Although not officially seen as a PROMs study, there are some studies that have focused on health related quality of life (HRQOL) in this patient group. Sarica et al. performed a study of 67 patients reported that after treatment with URS or ESWL, HRQOL scores increase after 6 weeks, but that there is no difference between the two different forms of treatment [18]. Another study even reported that HRQOL is better in previously treated patients (with ESWL and URS) compared to healthy controls after 3-15 months [19].

Other studies found that the number of URS treatments and stent placements negatively influenced HRQOL [20] and that residual fragments after ESWL treatment negatively influence HRQOL [21]. Other factors that might influence HRQOL are BMI, age and number of surgical interventions and stent placements [20]. One study also reported that women have lower scores HRQOL [22]. In our study however, there were no differences in QoL if we compared men and women. Also, QoL was not influenced by age, BMI, being a first time or recurrent stone former or number of ESWL treatments experienced by the patients.
The influence of having a JJ catheter could not be investigated due to the small group size.

The exact pain medication used before intervention was not registered, which might influence pain scores also during and after treatment. Other factors can influence pain scores as well, for example success of the procedure or waiting time prior to the procedure. These factors were not analysed. Also, since ESWL treated patients filled in the questionnaire directly after treatment and URS patients a day after treatment, direct comparing of pain scores during treatment is difficult.

This is the first study in the Netherlands in which different treatments for urolithiasis were researched using PROM. Compared to literature we had a high response rate (questionnaire 1: 68.9\%, questionnaire $1+2: 56.8 \%)[23,24]$.

Another strength is that patients filled in two questionnaires which made it possible to compare the results of baseline, directly after treatment and after 10-14 days follow up.

A weakness of the study is the limited number of participants which makes statistical (sub)-analysis difficult. Furthermore, although the questionnaire was designed with great care and for the general proms usage was made of the validated EQ5D-5L, the total questionnaire used in the study was not previously validated.

To conclude, with this study we made a start with PROMs and PREMs for urolithiasis patients. It shows that urolithiasis treatment has influence on patient's life. More knowledge in this area will improve shared decision making. Within the SENN we can use the experiences and results from this study to go through an efficient process aiming to implement practical PROMs and PREMs.

Open Access This article is distributed under the terms of the Creative Commons Attribution 4.0 International License (http://creativecommons.org/licenses/by/4.0/), which permits unrestricted use, distribution, and reproduction in any medium, provided you give appropriate credit to the original author(s) and the source, provide a link to the Creative Commons license, and indicate if changes were made.

\section{References}

1. Zonneveld WCG. Urolithiasis. In: Glas AS, Sedelaar JPM, van de Woestijne P, editors. Het urologie formularium. Formularium reeks. 2e herziene druk. Houten: Bohn Stafleu van Loghum;2015. pp. 183-93.

2. Patel N, Brown RD, Sarkissian C, De S, Monga M. Quality of life and urolithiasis: the patient-reported outcomes measurement information system (PROMIS). Int Braz J Urol. 2017;43(5):880-6.

3. Lotan Y. Economics and cost of care of stone disease. Adv Chronic Kidney Dis. 2009;16(1):5-10.

4. Ellison JS, Williams M, Keeley FX Jr. Patient-reported outcomes in nephrolithiasis: can we do better? J Endourol. 2018;32(1):10-20. 
5. Baumhauer JF, Bozic KJ. Value-based healthcare: patientreported outcomes in clinical decision making. Clin Orthop RelatRes. 2016;474(6):1375-8.

6. Porter ME. What is value in health care? N Engl J Med. 2010;363(26):2477-81

7. Rothrock NE, Hays RD, Spritzer K, Yount SE, Riley W, Cella D. Relative to the general US population, chronic diseases are associated with poorer health-related quality oflife as measured by the Patient-Reported Outcomes Measurement Information System (PROMIS). J Clin Epidemiol. 2010;63(11):1195-204.

8. Nivel. Kwaliteit vanuit patiëntenperspectief: CQ-Index, PREMs en PROMs 2018. 2019. Available from https:// www.nivel.nl/nl/kwaliteit-vanuit-patientenperspectiefcq-index-prems-en-proms. Accessed 12 Nov 2019.

9. Weldring T, Smith SM. Patient-reported outcomes (PROs) and patient-reported outcome measures (PROMs). Health Serv Insights. 2013;6:61-8.

10. Narang GL, Pannell SC, Laviana AA, Huen KHY, Izard J, Smith AB, et al. Patient-reported outcome measures in urology. Curr Opin Urol. 2017;27(4):366-74.

11. Penniston KL, Antonelli JA, Viprakasit DP, Averch TD, Sivalingam S, Sur RL, et al. Validation and reliability of the wisconsin stone quality of life questionnaire. J Urol. 2017;197(5):1280-8.

12. BorofskyMS, Lane GI, Neises SM, PortisAJ.Patient-reported outcomes measurement system (PROMIS(R)) for patients with urolithiasis: initial report. J Urol. 2017;198(5):1091-7.

13. EuroQol Research Foundation. EQ-5D-5L user guide. 2019. Avalilable from https://euroqol.org/publications/ user-guides. Accessed 12 Nov 2019.

14. Zee KI van der, Sanderman K. Het meten van de algehele gezondheidstoestand met de Rand-36. 2edruk. Groningen: UMCG / Rijksuniversiteit Groningen; 2012.

15. Foster A, Croot L, Brazier J, Harris J, O'Cathain A. The facilitators and barriers to implementing patient reported outcome measures in organisations delivering health related services: a systematic review of reviews. J Patient Rep Outcomes. 2018 Oct 3;2:46.

16. Zorginstituut Nederland. PROM-toolbox. 2019. Available from https://www.zorginzicht.nl/ontwikkeltools/promtoolbox. Accessed 12 Nov 2019.
17. Ragab M, Baldin N, Collie J, Tran MGB, Al-Hayek S, Parsy K, et al. Qualitative exploration of the renal stone patients experience and development of the renal stone-specific patient-reported outcome measure. BJU Int. 2019; https:/ / doi.org/10.1111/bju.14873.

18. Izamin I, Aniza I, Rizal AM, Aljunid SM. Comparing extracorporeal shock wave lithotripsy and ureteroscopy for treatment of proximal ureteric calculi: a cost-effectiveness study. Med J Malaysia. 2009;64(1):12-21.

19. Arafa MA, RabahDM. Study of quality of life and its determinants in patients after urinary stone fragmentation. Health Qual Life Outcomes. 2010 Oct 19;8:119.

20. Bensalah K, Tuncel A, Gupta A, Raman JD, Pearle MS, Lotan Y. Determinants of quality of life for patients with kidney stones. JUrol. 2008;179(6):2238-43. discussion 43.

21. Sahin C, Tuncer M, Yazici O, Horuz R, Cetinel AC, Eryildirim B, et al. Do the residual fragments after shock wave lithotripsy affect the quality of life? Urology. 2014;84(3):549-54.

22. Penniston KL, Nakada SY. Health related quality of life differs between male and female stone formers. J Urol. 2007;178(6):2435-40. discussion 40.

23. WillikEM van der, Leegte M, Ittersum F van, Prantl K, Bart H, Dekker F, et al. First Dutch registry of patient reported outcome measures (PROMs) has a low response in dialysis patients. NephrolDial Transplant. 2018;33(1):1.

24. Health and Social Care Information Centre. Patient reported outcome measures (PROms) in England, special topic: rates of attribution. 2016. Available from https://files. digital.nhs.uk/publicationimport/pub20xxx/pub20625/ proms-spec-topi-attr-rate.pdf. Accessed 12 Nov 2019.

drs. Janneke B.M. Jacobs, basisarts

drs. Saskia Weltings, aios urologie en promovendus

prof. dr. Rob C.M. Pelger, uroloog

dr. Barbara M.A. Schout, uroloog 